\title{
A NEW CONSIDERATION OF HEREDITARY CHOREA.*
}

BY R. M. PHELPS, M.D., First Assistant Physician, Second Mimesota Hospital for the Insane, Rochesțer, Minnesota.

$\mathrm{H}$

EREDITARY chorea, or Huntington's chorea, has attracted some attention during the past six years, considered variously as a new form of the disease, chorea, or as an entirely new disease. So new is it that hardly any mention of it is to be found in the text-books of the time. It is, however, beginning to assume a more well-defined form. An acquaintance with several cases of this disease has made me feel keenly interested in the few and slight references and the few articles that have appeared in the current medical literature; for in current literature is to be found almost all that is to be known of the disease.

To bring the disease plainly before you, for the consideration which is to follow, I will attempt a definition.

Hereditary chorea is a disease, manifested by choreic movements, beginning at adult life (usually about forty); commencing insiduously and increasing slowly, but steadily; having a strong and almost always effective tendency toward mental weakness, irritability, and dementia; and. progressing inevitably toward exhaustion and death.

A brief page of review of the growth and literature of the subject is almost essential as a preliminary to its study. By an examination of the writings upon the disease, we find that it was first noticed in print, in Dunglison's Practice, in I84I, he giving a letter from Dr. Waters, of Franklin, N. Y., describing the disease. Dr. Lyon, in 1863 , reported three representative cases, ${ }^{1}$ as indicating

* Presented to the American Neurological Association, at New York, June 22, 23 and 24, 1892. 
a disease, new (to him) in medical literaturc. Dr. Huntington, in 1872 , read a paper ${ }^{2}$ on Chorea, at Middleport, Ohio, and first succeeded in calling much attention to the hereditary form. He describes it (as far as he has learned) as only found at the eastern end of Long Island, where he, his father, and grandfather had lived, and had noted its progression.

So evidently few were the cases that Sinkler, in $1889,{ }^{3}$ reports that only nine writers had reported cases. Of these, only one writer was in this country. Clarence King," in I885, reports a case in an inaugural thesis, and again, another in I886, and a third in I889. Clarence King's father also lived in Long Island, and he theorizes that all of the cases might be, perhaps, traced to an origin there.

Landouzky reported a case in 1873 ; Ewald, two cases in 1885 ; Peretti, a case in 1885 ; Huber, a case, with review, in I887; Lepilli, a review, in I888; West, some cases in I887; Zacher, a case in I888; Hoffman, a case or series in 1888 ; Lannois, a series and a review in I888. Sinkler, in I889, gives a very complete review of these preceding cases, and adds two cases. Herringham, ${ }^{5}$ in 1888 , considers the subject. Kornhiloff, Biernacki, and Jolly have reported cases. In this country, Bower ${ }^{b}$ has reported two cases. In 1889, Diller ${ }^{7}$ makes the first report representing insane asylum population. Seemingly, this element should have been thought of earlier in consideration of the strong tendency toward dementia in these cases. Hay, in I890, makes further report, representing the same element in population. In March of the present year, Sinkler ${ }^{9}$ again presents a paper, bringing the subject up to date, and adding two cases from the Philadelphia Hospital wards.

With four more or less comprehensive reviews of the subject, three of them in this country in the last four years, I am not, therefore, writing for a review, but to take the standpoint already attained and to advance both new cases and comments upon the subject.

The subject, as thus far developed, is that of a com- 
paratively few number of families, in which the disease appears at adult life, with more or less distinct heredity.

In considering the literature and my own cases, there was one indication, it seemed to me, in favor of another presentation, besides the typical cases to be presented. The thought lay in this way: The cases so far reported have been chiefly reported as developing locally and as few and rare. Probably they seem rare, simply because the only ones these observers have heard from, while they may be proportionally as common all over the United States.

This thought was given strength by the fact that we had had five cases of adult chorea in our asylum, or one to six hundred admissions. Of these, three had a clear histury of heredity; while of the other two the history was not obtainable. These cases, tending to come to insane asylums, on account of their mental weaknes, I wrote a circular letter to fifty insane asylums of the United States, representing all parts of the country. I have received replies from twenty-four different asylums.

Of these twenty-four asylums, eight asylums report eleven cases and two more in the past records, of which the history is not furnished. Thirteen cases are reported which I cannot include, because of the doubtful or unknown heredity. Four asylums report no chorea of any form; five specify no chorea of hereditary character. The results of this investigation, therefore, have not been so great as I had hoped. And yet I am able to report a number of new cases, equal to one-third of those previously reported, though they have somewhat meager histories attached. I have prepared a table as an appendix to, but separate from, this paper collecting the thirtythree series reported by other authors, which I have found given in sufficient detail; and, also, the thirteen new cases herewith reported by myself. These I have gathered in statistical form, trusting to thus bring the subject in a more comprehensive and impressive way to the consideration of the profession. 
Having placed them thus in tabular form, I will but speak briefly of the cases now reported by myself.

CASE I.--Reported by J. W. Waughop, Superintendent of the Hospital for Insane, Fort Steilacoom, Washington. Female, living, married, age thirty-five years, four children, admitted in I887. Has intense choreic movements of "twelve years' duration." "Her mother was affected as she now is;" "brother insane." Recently her oldest son has become choreic. She retrograded steadily in mind, as in "senile dementia," but, at the same time, had "delusions of grandeur" ("God is my lawyer") like a paretic.

CASE II.-Reported by Frank Norbury, M.D., Assistant Physician, Jacksonville, Ill. Patient, female, age thirty, divorced; chorea appeared seven years ago, has gradually grown worse; has been insane two and a half years; mind impaired, but fairly intelligent; symptoms "like apathetic imbecility;" no paretic symptoms; delusions of suspicion; knee-jerk increased; "cannot walk without assistance;" father was affected "late in life," and mind not much impaired.

CASES IV. AND V.-Reported from the Connecticut Hospital for the Insane, give only the statistical facts. No. 4 was choreic to death; at age of sixty-six showed progressive dementia, and father had same form of trouble. No. 5, male; choreic to age of fifty-four, living; disease progressive, and mother choreic in same way.

Case VI.-Reported by Wm. B. Hall, Assistant Physician, Tuscaloosa, Ala. Female, age twenty-six, admitted I 888; has steadily progressed since. There is considerable of dementia present; no paresis; father choreic; patient has also "chronic nephritis." .

CASE VII.-From Taunton Lunatic Hospital; has no details given. Patient choreic from forty-nine to death; father choreic in same way; mental state like acute mania.

CASE VIII.-Reported from Danver Lunatic Asylum. Patient choreic from the age of forty-one to death, at forty-six; progressive form; mental state resembles general paresis more than senile dementia. At the "incep- 
tion of the trouble showed excitement and expansive ideas, followed by secondary dementia." The mother and mother's sister suffered in same way.

Case IX.-Dr. A. Trowbridge, Assistant Physician, Danville, $\mathrm{Pa}$., reports a case just admitted, whose mother was reported as choreic, and one brother and a sister insane (perhaps choreic?). This patient had a record of maniacal attacks, though, in appearance, "imbecile."

Dr. Trowbridge, who has made special study of chorea and epilepsy, also says that there are present seven cases of adult and "congenital" chorea, which, on the whole, "differs in no respect from the hereditary form, either in appearance, course or termination."

Case X.-Reported by G. H. Hill, Superintendent, Independence, Iowa (in addition to two other cases previously in print). Patient, M., age thirty-five, living, shows chorea and progressive dementia. Patient's two sisters and her mother chorẹic.

Of the cases coming under my care, with undoubted heredity, I report three, as follows:

CASE I.-Female, age fifty-nine at death, married, nine children; chorea has been growing ten years. "Absent-mindedness" and "feebleness of mind" came on slowly and insidiously. Chorea grew along with mental trouble, as near as I can learn. She is said to have had early several "paroxysms of acute mania." On admission is said to "eat voraciously," and to "burn everything" as she gets opportunity. Admitted here, May, I888; died here, December, I889. While here was feeble-minded, quiet, and satisfied. Her talk was somewhat irrelevant; she claimed to get large amounts of money for staying here; had a satisfied air, however poor condition she was in, resembling in a mild way general paresis. She died of exhaustion, quietly and steadily, without fever, pain, cough or any complaint. Her mother, her mother's two sisters, and her mother's mother were choreic.

CASE II.-Female, age forty-two at death; admitted October, I889; died March, I890. Disease growing for fifteen years; only recently so bad as to need asylum 
care. Mental condition one of feeble-mindedness, like senile dementia, with despondency at her choreic condition. Has the most extreme trouble in eating; seems in great danger every meal. She holds food in mouth in clonic rigidity from one to four seconds, and then, with sudden gulp, swallows it down whole. Choking is frequent. Movements are so extreme, cannot feed herself at all. It is stated that "all of the family are more or less insane as they grow old." Her mother and sister were choreic; others also; but considerable correspond. ence fails to bring out the relationship.

CASE III.-Female, now aged fifty-three, living; admitted March, 189I; left unimproved January, I892; widow, two children. Her father died by suicide, after eight or ten years of progressive chorea of the same kind. A sister and a brother have the same trouble. The patellar reflex is considerably exaggerated, speech very thick as well as jerky. She manifests a quiet dementia, has a satisfied manner, not extreme, yet always present. Chorea and dementia progressive. Exhibits movements of whole body; facial movements; movements of hands; and walks in a jerky way.

Besides these three typical cases, I have two others whose history is completely unknown, but whose disease is so typical in its elements, that I have always, in my personal opinion, included it in the same category. Though I have rigidly thrown out a large number of cases reported by others, because heredity was "unknown," or the disease of ancestors noted simply as "insanity," yet I will include these two with this explanation and with special purpose.

CASE IV.-Male, age about fifty; picked up in St. Paul; native of England. Exposure to cold while at work in Rocky Mountains is put down as cause. Admitted October 8, I885; died March, I892. During stay here showed a slow, gradual deterioration through all of the stages of growing weakness, both bodily and mentally. Talked of vasts amounts of property. Later, thought the Queen of England was his wife. Delusions were not systematized, but did not change rapidly, nor were they prominent. His talk was jerky and accompanied by jerks and cortortions of limbs, body and face. 
He walked always in a shuffling, hesitating manner. His dementia was such that we were never able to get his previous history from him. Patellar reflex exaggerated. He died from exhaustion in a lingering way, just as from general paresis. He had always a quiet, satisfied mind.

CASE V.-Male, age forty-seven; admitted August, I 890; married; also picked up in St. Paul. His delusion was that he was to get a million dollars for standing back and allowing Harrison to be President instead of himself. Exalted ideas constant, but rarely spoken of. Dementia quite profound. He says his brother and others are the same as he is. It is almost impossible to get history from him, in spite of willingness to talk; has a quiet, satisfied manner; has had several excitable spells; is now living.

From these cases what do we learn concerning prominent characteristics? The most prominent one, or the one made most prominent, is heredity. But most asylum observers note cases in which no history of heredity is given. If these were few enough, they could be considered as the first of a family series. But the testimony indicates that the number without history of heredity exceeds, by several times, the number known to be hereditary. 'This fact was also found true by Diller," in his similar investigation. With such scant history as comes to an insane asylum, it is probable that many of these are hereditary. But, by a general form of reasoning, it would seem very reasonable to suppose that the cases not having heredity and the cases of unknown heredity, if they manifest the same symptoms, in the same progressive way, and finally die in the same state of exhaustion, would have the same pathological findings, and, indeed, be practically the same disease. This reasoning has, however, been slighted by writers, and the tendency has been to speak of the disease as a distinctly new discovery. Then, too, these series must all have a beginning.

In my table, however, selected by heredity, a more strongly marked heredity than is seen in almost any other disease is prominent as a symptom. 
The next most important element is a progressive nature toward dementia, exhaustion, and death.

Most of the cases die of the choreic exhaustion in about the same manner as general paretics die. It seems probable that all would so die if the duration did not allow of intercurrent affections. This progressive character belongs to the chorea (as well as to the mental state) and the chorea frequently begins as a local trouble, gradually becoming general.

The next important element is probably the clacacter of the mental change. Although different words are used to describe it, it seems to me essentially the same in all cases, reading through the terms used, as I do, by means of context and is usually a quite symmetrical brain failure. For instance, one case is spoken of as melancholia and going on to dementia. Knowing that the dementia may have, as many senile dementias do have, a melancholic or maniacal tinge from the start, I, by the hints added, infer it to have been essentially dementia from the beginning. Nearly all reports, however, speak unmistakably of "dementia" or "weak-mindedness," coupled very frequently with somewhat of early irritability or violence.

Last March I took occasion to call attention in print ${ }^{12}$ to the general broad resemblances between general paresis and hereditary chorea. I thought myself to be the first one noting the same, but see later that Hoffman ${ }^{13}$ makes passing note of the same resemblance from the standpoint of the finding of "meningitic lesions" and "cortical atrophy."

Although I started from a quite widely differing standpoint, it seems to me that, as shown by my five cases (three watched until death), as the two diseases progress, they come together into quite closely similar conditions, and finally die in about the same exhausted way-exhaustion, not from activity, but apparently from a gradual withdrawing of life-power from the nerve centres.

At least this is the impression made upon me by my 
cases; and the clinical histories given by others seem to indicate exactly the same course of the disease. Let us look at the points of similarity.

I. It begins at adult life. This is as distinctive a feature as of general paralysis, and if one is to be regarded as a phenomenon of premature senile degeneration, so may the other as well. Whatever significance the one has, the other may have in like manner.

2. The mental change is essentially a dementia. In a tabulated series of over sixty cases of general paresis, personally examined, I find about one-half persuing a fairly steady mental degeneration, with little of the excited stage. On the other hand, many of these choreics present early irritability and violence. In early stages, therefore, the diseases are not far apart. Later, the mental states approximate quite closely. In four out of five cases of chorea personally seen, there was the same quiet mental satisfaction to the last. (In the other was mental feebleness, with a despondent, half-realizing sense of her physical condition.)

Still further, in two of my cases there were (somewhat feebly exhibited) the same exaggerated ideas as in general paresis. There was not, however, the facility in changing delusions, and the unsystematized character as in the extreme forms of paresis, but they quite closely resembled the quieter cases.

3. Motor appearances. These, though similar in appearance, seem to have widely different origin at first: the one, an inco-ordination of voluntary movement; the other, a series of involuntary movements. Still, the facial sluggishness toward the last, the clumsy use of hands, feet and tongue, and the general physical and mental helplessness present almost the same clinical appearance.

4. Duration. This is often two or three times as long as general paresis. But, perhaps, this more gradual mental and physical invasion.would account for the less acute character of mental symptoms, and the lack of so pronounced excited stage. 
5. The progressive and uniformly fatal character of the disease is about the same in both cases.

Now, with so much of similarity in motor and mental changes, is it unreasonable to expect as clearly allied pathological lesions? The Annual, of i 890 , sums up pathological findings as three: McLeod (doubtful case) subdural hemorrhagic cyst; Huber, one case, with pachymeningitis and leptomeningitis; Klebs, one case, unknown. Since that time, Sinkler" has reported an autopsy with findings of meningeal congestion and œdema, and with dura thick, tough and adherent, and with microscopical examination rather indeterminate. Osler ${ }^{14}$ has reported one case with a record of "meningitic signs" and with "cortical atrophy."

The two previous deaths from the disease, which occurred here, gave me no opportunity for post-mortem. But this year the death of number five (although I am not sure of heredity in his case), of typical character, gave me the coveted opportunity.

The gross appearances consisted of moderate adhesions and thickening of dura mater, with a pachymeningitis of the convexity. Atrophy of brain, especially the anterior part, was manifest at a glance on removal of dura. Serous accumulations were found under the dura and in the pia arachnoid. A kind of milky, plastic serous exudate was found, thickest on the convexity and in the sulci of the brain. This was whitish, and this combination was similar to the customary gross appearances of general paresis as found here, except in the amount of serous accumulation, and in its greater fluidity and the sponginess of the pia arachnoid. A pearly or ground-glass appearance of the floor of lateral ventricle was noticeable; also congestion of choroid plexus, and a cystic formation of the same in right lateral ventricle. Weight of brain, with pia, was $39 \frac{3}{4}$ ounces.

The brain and cord presented no other gross lesions which wcre observed. It is now hardening in fluid for microscopical examination, and I hope later to report 
microscopical findings. In regard to gross cerebral appearances (whether the case be hereditary or not), it will be seen that I have to record a finding resembling, in a general way, the findings in cases of general paretics, as I before suspected possible from clinical observations. This gross pathological finding is, perhaps, not conclusive of anything, but it is quite suggestive.

This form of reasoning by analogy and from similar effects back to similar causes, is very attractive. It can, it seems to me, be used to form a working hypothesis. And the hypothesis once formed in this case, it is somewhat surprising to note the amount of evidence that falls into line. In like manner, if, in the future, hereditary chorea be clearly shown to have its pathology in the cerebral cortex, we can look back to simple chorea and note its slight mental changes, their similar character of symmetrical brain failure; the similar motor disturbances; and note also the now recognized fact that heredity in nervous and mental diseases is not by the identical disease, but in varying and chance directions, and argue the lesion to be a cerebral and cortical one.

In current literature we find similar tendencies, and strong ones. Recently, Trowbridge has shown strong analogies between chorea and epilepsy. Dr. Riggs ${ }^{15}$ has restated the relationships of epilepsy and migraine, and Hoffman reports a case of adult chorea, with epileptic ancestors, which he considers "hereditary." Athetosis, seems also to have links of relationship to chorea.

In conclusion I would simply record my conviction that hereditary chorea is not so rare as previously thought, and that as knowledge of it becomes more general, cases will be found in all parts of the country; that the element of heredity will probably be set aside as only an extra-strong, predisposing cause, and the term "chronic progressive chorea" will accurately describe the condition; that as insane asylums will doubtless receive a large proportion of these cases, they should be urged to secure autopsies for the better elucidation of the disease; that modern literature shows a tendency to 
find relationship between these motor-disturbance diseases, which might possibly also extend to general paresis.

Finally, I would also insist, with conviction, upon the need and appropriateness of another term in our tables of mental disease. Choreic dementia designates a dementia on equal footing and right with paretic dementia, epileptic dementia, and senile dementia.

\title{
REFERENCE LIST.
}

\author{
I. American Medical Times, Dec. I9, I863. \\ 2. Medical and Surgical Reporter, Philadelphia, April I3, I892. \\ 3. Journal Nervous and Mental Disease, Feb. I8, I889. \\ 4. N. Y. Medical Jourual, I885, p. 468; Med. Press of Western New \\ York, Dec., I886; Philadelphia Med. News, July, I889. \\ 5. Brain, Oct., I 888 . \\ 6. Journal Nervous and Mental Disease, March, i 890. \\ 7. American Journal Med. Sciences, Dec., I890. \\ 8. University Med. Magazine, June, I890. \\ 9. N. Y. Med Record, March I2, I892. \\ I0. Alienist and Neurologist, Jan., I892. \\ I I. Anlerican Journal Med. Sciences, April, ISgo. \\ 12. Hospital Bulletin, Second Minn. Hospital for Insane, Feb., IS92. \\ 13. Anliual of Universal Med. Sciences, ISgo. \\ I4. Practice of Medicine. \\ I5. N. W. Lancet, May I, I892.
}

\section{AN ACUTE MYXGDEMATOUS CONDITION OCCURRING IN GOITRE.}

Dr. Osler recently presented to the Johns Hopkins Hospital Society a case which he regarded as very probably an instance of acute myxœedma occurring with enlargement of the thyroid.

The patient was of.good antecedents and had never been ill. Present trouble began three months ago with constipation, stomach disorder, chilliness at times, and then swelling began in the face and hands, sometimes in the muscles of the arms. Face decidedly swollen and has remained so. Simultaneous swelling of thyroid gland. General health otherwise very fair. Face looks swollen and puffy, colorless lips and conjunctiva, no exopthalmos, thyroid symmetrically enlarged; pulsation marked. Under use of fluid extract of ergot the patient has decidedly improved. Face still looks a little enlarged, but hands are not swollen. He is able to work, and there is no trace of mental impairment. 